\title{
REVIEW
}

\section{Melatonin in Chronic Pain Syndromes}

Andrei Danilov $\cdot$ Julia Kurganova

Received: November 27, 2015 / Published online: March 16, 2016

(C) The Author(s) 2016. This article is published with open access at Springerlink.com

\section{ABSTRACT}

Melatonin is a neurohormone secreted by epiphysis and extrapineal structures. It performs several functions including chronobiotic, antioxidant, oncostatic, immune modulating, normothermal, and anxiolytic functions. Melatonin affects the cardiovascular system and gastrointestinal tract, participates in reproduction and metabolism, and body mass regulation. Moreover, recent studies have demonstrated melatonin efficacy in relation to pain syndromes. The present paper reviews the studies on melatonin use in fibromyalgia, headaches, irritable bowel syndrome, chronic back pain, and rheumatoid arthritis. The paper discusses the possible mechanisms of melatonin analgesic properties. On one hand, circadian rhythms normalization results in sleep improvement, which is inevitably disordered in chronic pain syndromes, and activation of

Enhanced content To view enhanced content for this article, go to http://www.medengine.com/Redeem/ AB44F0607052BC6E.

A. Danilov $(\varangle) \cdot$ J. Kurganova Department of Neurology, Postdegree Training Institute, I.M. Sechenov First Moscow State Medical University, Moscow, Russia

e-mail: andreidanilov@mail.ru melatonin adaptive capabilities. On the other hand, there is evidence of melatonin-independent analgesic effect involving melatonin receptors and several neurotransmitter systems.

Keywords: Chronic pain; Fibromyalgia; Headache; Irritable bowel syndrome; Low back pain; Melatonin; Migraine; Rheumatoid arthritis

\section{INTRODUCTION}

The role of the circadian rhythm in human life has been well known for a long time. The notion of the circadian rhythm introduced by Franz Halberg in 1959 overturned researchers' understanding of many processes in the human body. It was found that circadian rhythms are involved in several physiological processes, such as the sleep-wake cycle, body temperature regulation, hormone secretion, cell division and proliferation, gastro-intestinal tract function, etc. Circadian rhythm disorders may result in several pathological conditions, while most diseases may cause circadian 
desynchronization. For example, chronic pain syndromes are always associated with various degrees of biological rhythm desynchronization. The biological rhythms in mammals are controlled by the suprachiasmatic nuclei of the hypothalamus. The suprachiasmatic nuclei that cannot receive light signals directly, receive them via an optic nerve passing the information from the retina [1]. Another important organ involved in biological rhythm regulation is the epiphysis or the pineal gland. The epiphysis is an endocrine gland in the diencephalon area above the superior colliculus of the midbrain. The epiphysis synthesizes and secrets neurohormone melatonin. It is noteworthy that though epiphysis secrets $80 \%$ of melatonin, there are extrapineal sources of melatonin: cells of gastrointestinal tract (GIT), lungs and renal cortex, eye retina, lymphocytes, thrombocytes, mastocytes, etc. Some melatonin properties are well known; the others are still under study. Melatonin has chronobiological features, can regulate circadian rhythms, and normalize sleep. Moreover, melatonin demonstrated antioxidant functions, which were laid into the foundation of its use in neurodegenerative diseases, e.g., Parkinson and Alzheimer's diseases [2]. Several experimental and clinical studies have revealed new melatonin properties such as oncostatic and immune-modulating effects, the capability to improve mood and to decrease anxiety, to affect the cardiovascular system and GIT, as well as the role of melatonin in reproductive functions and metabolism and body mass regulation [3]. The analgesic capabilities of melatonin have always attracted much interest. Given that the contemporary therapy of chronic pain syndrome is far from perfect, constant search is required for new molecules with analgesic capabilities as well as the research into the existing substances used in the treatment of other conditions. The decisive factor is the combination of high efficacy and good safety profile of a drug [4]. Melatonin demonstrated efficacy and safety in nociceptive and neuropathic pain in several studies on animal models and clinical trials.

\section{Compliance with Ethics Guidelines}

This article is based on previously conducted studies and does not involve any new studies of human or animal subjects performed by any of the authors.

\section{MELATONIN IN EXPERIMENTAL RESEARCH (TABLE 1)}

Yet in 1991, using a hot plate test in a nociceptive pain model, Golombek et al. [5] demonstrated that intraperitoneal injection of $20-40 \mathrm{mg} / \mathrm{kg}$ of melatonin produced the strongest analgesic effect if administered in the evening. The analgesic effect decreased after the administration of opiate antagonist naloxone or central benzodiazepine (BZD) antagonist Flumazenil suggesting the involvement of the central opioid and BZD receptors [5].

In a different study on a nociceptive pain model, $\mathrm{Yu}$ et al. [6] demonstrated the dose-dependent effect of melatonin using a group of rats that received intraperitoneal melatonin injections in various doses $(30,60$, $120 \mathrm{mg} / \mathrm{kg}$ ) combined with pain stimulation. The antinociceptive effect took place at $15 \mathrm{~min}$ after injection of $60-120 \mathrm{mg} / \mathrm{kg}$ of melatonin, peaked at $30 \mathrm{~min}$, and continued for $100 \mathrm{~min}$. The intravenous injection of naloxone neutralized the melatonin analgesic effect in 10 min [6]. Several other studies confirmed that 
melatonin might be effective in relation to nociceptive pain. El-Shenawy in 2002 [7], Esposito in 2010 [8], and Mantovani in 2003 [9] demonstrated melatonin analgesic capabilities in relation to nociceptive pain in their experiments. Melatonin inhibited prostaglandins release and suppressed polymorphonuclear leukocytes integration at the inflammation site and suppressed inflammation inhibiting COX-2 and NO-synthase.

It is noteworthy that in the experiments, melatonin also demonstrated its efficacy in neuropathic pain. In 2004, Tu et al. [10] showed that melatonin administration decreased the intensity and duration of capsaicin-induced secondary mechanical allodynia and hyperalgesia, suggesting that melatonin effect on the CNS can hinder the onset and generalization of "central sensitization", resulting from capsaicin injection. In 2006, Ulugol et al. [11] demonstrated melatonin efficacy in relation to neuropathic pain. In the study on mice, sciatic nerve ligation causes pain associated with mechanical allodynia and thermal hyperalgesia. High-dose (120 mg/kg) melatonin intraperitoneal injections and $0.1 \mathrm{nmol}$ intravenous infusion resulted in the increase of the pain threshold and a decrease of thermal hyperalgesia manifestation [11].

\section{MELATONIN CLINICAL TRIAL EXPERIENCE (TABLE 2)}

\section{Melatonin in Migraine}

There was much discussion recently that circadian rhythm disorders play an important role in the pathogenesis of headaches. In this situation, melatonin can decrease the frequency and intensity of pain syndromes through inherent analgesic mechanisms and circadian rhythm normalization. Melatonin receptors were found in the ganglia and nuclei of the trigeminal nerve, suggesting that melatonin decreases trigeminal vascular nociception. Several studies analyzed the association between night melatonin secretion and migraine. The study involving 146 migraine patients revealed a substantially lower urinary level of 6-sulphateoxymelatonin (basic melatonin metabolite) in migraine patients compared to a group of healthy volunteers [12].

Another study involving 34 patients assessed melatonin efficacy in migraine prevention. Peres et al. [13] demonstrated that $3 \mathrm{mg}$ of melatonin before sleep can decrease the frequency, intensity, and duration of pain in migraine patients. In a recent study, the melatonin agonist agomelatine was successfully used in the treatment of migraine patients who took $25 \mathrm{mg}$ /day of agomelatine for 3 months, leading to a decrease in migraine attack frequency and duration. Moreover, agomelatine treatment resulted in depression level decrease and sleep normalization in these patients [14].

\section{Melatonin in Cluster Headaches}

The pathophysiology of cluster headaches remains unclear, but modern concepts suggest the involvement of circadian rhythms in the pathogenesis of this disease; the studies revealed a decrease of night melatonin secretion in the cluster headache patients compared to the healthy controls as well as lower melatonin level during the cluster headache attacks compared to the remission period [15]. In a clinical study, cluster headache patients received $10 \mathrm{mg}$ of melatonin or placebo before sleep for 
14 days. The study revealed a significant decrease in the intensity and frequency of attacks in the study group compared to the control group. Moreover, the study group showed a tendency towards the decrease of analgesic intake compared to the control group though the difference was insignificant [16]. In a different study, the cluster headache patients took $2 \mathrm{mg}$ of melatonin, however no significant difference in the pain syndrome compared to the control group was found; the findings can be explained by a low melatonin dose [17].

\section{Melatonin in Tension Headaches}

Melatonin demonstrated efficacy in tension headaches. Miano et al. [18] studied the possibility to prevent tension headaches in children. The study involved 21 participants who took $3 \mathrm{~g}$ of melatonin before sleep for 3 months. After the therapy, 14 of 21 patients reported a $50 \%$ or more decrease in the pain syndrome intensity, and four of them experienced no pain attacks at all [18].

\section{Melatonin in Chronic Back Pain}

The efficacy of melatonin in chronic back pain was then assessed in a study involving 178 patients (aged 40-65 years) with lower back pain over three points measured on a visual analogue scale for at least 12 months. The patients were stratified into six groups making three comparison pairs. The patients in study group $1 \quad(n=31)$ took one tablet of $\operatorname{Artra}^{\circledR}$ (Unipharm, Inc.; combination of $500 \mathrm{mg}$ glucosamine hydrochloride and $500 \mathrm{mg}$ chondroitin sulfate) twice a day for 1 month, then one tablet a day for 2 months and additionally Melaxen ${ }^{\circledR}$ (Unipharm, Inc.; $3 \mathrm{mg}$ of melatonin 30-40 min before sleep), the patients from the comparison group $(n=29)$ took Artra only. The patients in comparison group $2(n=30)$ took one tablet of Artra twice a day and $25 \mathrm{mg}$ of diclofenac 2-3 times a day. The patients in study group $2 \quad(n=30)$ additionally took Melaxen (3 $\mathrm{mg}$ of melatonin 30-40 min before sleep). The patients in study group 3 ( $n=29)$ took $25 \mathrm{mg}$ of diclofenac three times a day and Melaxen (3 $\mathrm{mg}$ of melatonin 30-40 min before sleep). The patients in comparison group $3(n=29)$ did not take Melaxen. The results in group 1 were evaluated in 3 months, and in groups 2 and 3 in a month. The findings suggested significantly more expressed decrease in pain both in motion and at rest in the study groups compared to the comparison groups. Moreover, the patients demonstrated less influence of pain in daily activities, a decrease in anxiety and depression, and sleep normalization. That led to a conclusion that the addition of melatonin to the standard treatment scheme increases its efficacy in back pain [19].

\section{Melatonin and Irritable Bowel Syndrome}

Besides the epiphysis melatonin is synthesized by enterochromaffin cells in the GIT suggesting melatonin involvement in physiology and pathologies of the GIT. Melatonin synthesis and secretion in the GIT do not follow 24-h cycles. Melatonin stimulates macrophage inhibition and decreases the release of inflammatory mediators, preventing GIT mucosa ulceration and damage to the large intestines. Melatonin can decrease abdominal pains and facilitate defecation, not affecting anxiety and sleep in irritable bowel syndrome patients [20]. On the other hand, there is evidence suggesting the positive impact of melatonin on extra bowel symptoms in irritable bowel syndrome resulting from either anxiolytic or direct effect on the GIT [21]. 
Two randomized placebo-controlled clinical trials dealt with melatonin analgesic effects in irritable bowel syndrome patients. In both studies, the patients took $3 \mathrm{mg}$ of melatonin. One study involved 40 patients who took either placebo or melatonin for 2 weeks [22]. The other study involved 17 patients who took either placebo or melatonin for 8 weeks with a 4-week "washout" period [23]. In both of the clinical studies, the patients reported a significant decrease in pain intensity compared to the control groups.

Chojnacki et al. [24] demonstrated that 6-month melatonin administration improves the bowel movement and abdominal pain decrease.

\section{Melatonin in Fibromyalgia}

Melatonin secretion disorder may be a part of fibromyalgia pathogenesis. However, the clinical evidence is controversial. Several studies analyzed the circadian rhythms and melatonin secretion in fibromyalgia patients. For example, one study revealed no significant differences in melatonin level in the fibromyalgia patients and in healthy people [25], while another study found significantly lower urine melatonin concentration in the fibromyalgia patients compared to the healthy controls [26].

A study was conducted in Russia to investigate the effect of 10-day evening administration of $1.5 \mathrm{mg}$ of melatonin (Melaxen) on the subjective assessment and instrumental evaluation of night sleep quality in 11 fibromyalgia patients. Polysomnography confirmed night sleep disorders: difficulty in falling asleep, a longer latent period of surface and paradoxical sleep, deep sleep suppression, the decreased number of completed sleep cycles, an increased number of wake periods and sleep movements, etc. After the treatment, the patients reported subjective sleep improvement, confirmed by polygraphic registration: ease of falling asleep and shorter wake periods during sleep, etc. The patients also reported feeling better, a decrease in depression, and better fine motor function of the hands in the daytime. The findings suggest melatonin positive effect on the sleep quality in the patients with sleep disorders. These patients also reported a certain decrease of pain and depression levels [27].

In another open randomized study involving 21 female patients, $3 \mathrm{mg}$ of melatonin was administered $30 \mathrm{~min}$ before sleep for 4 weeks. The patients reported significant sleep improvement and a decrease in the number of painful trigger points compared to the baseline level. The authors also reported good though insignificant results in relation to the therapy of pain, tiredness, and depressive symptoms [28].

Hussein et al. [29] did a double-blinded placebo-controlled study involving 101 fibromyalgia patients to assess the efficacy of various melatonin doses both separately and in combination with fluoxetine. The patients were stratified into four groups: group A patients took $20 \mathrm{mg}$ /day of fluoxetine, group B patients took $\mathrm{mg}$ /day of melatonin, group $\mathrm{C}$ patients took $20 \mathrm{mg} /$ day of fluoxetine in combination with $3 \mathrm{mg} /$ day of melatonin, group D patients took $20 \mathrm{mg} /$ day of fluoxetine in combination with $5 \mathrm{mg} /$ day of melatonin. The treatment with fluoxetine only resulted in a decrease of tiredness, morning stiffness, anxiety, and depression. Melatonin treatment produced less effect on these symptoms though it was significant in relation to pain, depression, anxiety, and sleep disorders. The combined therapy with melatonin and fluoxetine decreased anxiety, tiredness, and significantly limited depressive symptoms [29]. 
In 2014, de Zanette et al. [30] reported the results of melatonin treatment of fibromyalgia patients. Sixty-three female patients (aged 18-65 years) were randomized into three groups: group 1 took $25 \mathrm{mg}$ of amitriptyline before sleep, group 2 took $10 \mathrm{mg}$ of melatonin before sleep, and group 3 took a combination of $25 \mathrm{mg}$ of amitriptyline and $10 \mathrm{mg}$ of melatonin. The treatment duration was 6 weeks. The study revealed that a combination of $25 \mathrm{mg}$ of amitriptyline and $10 \mathrm{mg}$ of melatonin and isolated administration of melatonin were more efficient than amitriptyline in relation to pain, morning stiffness, and sleep disorders in fibromyalgia patients [30].

The pathophysiological relations between circadian rhythm disorders remain unclear though the efficacy of melatonin in such patients is demonstrated in several clinical trials with a high level of evidence.

\section{Melatonin and Rheumatoid Arthritis}

How is melatonin involved in the pathogenesis of rheumatoid arthritis? Compared to healthy people, rheumatoid arthritis patients have a significantly higher level of melatonin secretion at night; in the morning, the blood serum melatonin level is higher in patients with shorter disease history [31, 32]. Inflammation cytokines such as interferon-gamma, interleukin-1, and interleukin-6 are secreted into the peripheral bloodstream in response to melatonin stimulation, moreover, melatonin is found in the synovial liquid in rheumatoid arthritis patients [33]. These findings suggest that melatonin produces an unfavorable influence on rheumatoid arthritis. On the other hand, melatonin inhibits the activity of matrix metalloproteinase (MMP), which is involved in the joint destruction in rheumatoid arthritis patients [34]. Thus, the role of melatonin in joint destruction calls for additional studies.

\section{DISCUSSION OF POSSIBLE ACTION MECHANISMS}

Melatonin demonstrated an analgesic effect in several experimental studies and clinical trials. What is the underlying mechanism of this effect? On one hand, the normalization of circadian rhythms, which are inevitably disordered in chronic pain syndromes, leads to the improvement of sleep and activation of melatonin inherent adaptive capabilities. On the other hand, there is evidence of melatonin-inherent analgesic effect realized through receptors and several neurotransmitter systems.

\section{Melatonin Receptors}

There are membrane melatonin receptors $\mathrm{MT}_{1} /$ $\mathrm{MT}_{2}$ and nuclear melatonin receptors RZR $\alpha /$ RZR $\beta$. The membrane receptors involved in melatonin analgesic effect are indicated by $\mathrm{MT}_{1} / \mathrm{MT}_{2}$ receptors localization in the thalamus, the hypothalamus, the dorsal horns of the spinal cord, the spinal trigeminal tract, and the trigeminal nerve nucleus. Moreover, the experimental studies demonstrated that administration of luzindole, to $\mathrm{MT}_{1} / \mathrm{MT}_{2}$ melatonin receptors antagonist, or 4-P-PODT/ K-185 substances, $\mathrm{MT}_{2}$ receptors selective antagonists, decreases the antinociceptive effect. The studies showed that melatonin has a complex analgesic effect, which, however, is primarily based on the spinal nociception inhibition.

Melatonin receptor activation decreases the intracellular levels of cyclic adenosine monophosphate (cAMP) and cyclic guanosine 
monophosphate (cGMP) [35]. Melatonin inhibits such mediators as $\mathrm{Ca}^{2+}$, diaglycerol, inositol phosphate, and arachidonic acid, at least, in the anterior pituitary in rats [36]. Electrophysiological study demonstrated that melatonin activates calcium-dependent ion C1-channels through phospholipase and this effect can be inhibited by specific melatonin $\mathrm{MT}_{1} / \mathrm{MT}_{2}$ receptor antagonists [37]. It was suggested that melatonin can block calmodulin (CaM) interaction with specific enzymes [38]. This evidence is of great importance since CaM kinase plays a crucial role in central sensitization.

A recent experimental study evaluated the efficacy of a novel selective melatonin $\mathrm{MT}_{2}$ receptor partial agonist $\mathrm{N}$-\{2-([3-bromo phenyl]-4-fluorophenylamino)ethyl acetamide (UCM924) in two neuropathic pain models in rats and examined its supraspinal mechanism of action. In rat L5-L6 spinal nerve ligation and spared nerve injury models, UCM924 (20-40 $\mathrm{mg} / \mathrm{kg}$, subcutaneously) produced a prolonged antinociceptive effect that is: (1) dose-dependent and blocked by the selective $\mathrm{MT}_{2} \quad$ receptor antagonist 4-phenyl-2-propionamidotetralin, (2) superior to a high dose of melatonin $(150 \mathrm{mg} / \mathrm{kg})$ and comparable with Gabapentin $(100 \mathrm{mg} / \mathrm{kg})$, but (3) without noticeable motor coordination impairments in the rotarod test. Double-staining immunohistochemistry revealed that $\mathrm{MT}_{2}$ receptors were expressed by glutamatergic neurons in the rostral ventrolateral periaqueductal gray. In vivo electrophysiology combined with tail flick showed that microinjection of UCM924 into the ventrolateral periaqueductal gray decreased tail flick responses, depressed the firing activity of ON cells, and activated the firing of OFF cells; all effects were $\mathrm{MT}_{2}$ receptor-dependent [39]. In a different study, López-Canul et al. [40] studied antiallodynic effects of $\mathrm{MT}_{2}$ receptor agonists on animal neuropathic pain models by $\mathrm{ON}$ - and OFF-cells activation. The study involved $\mathrm{N}$-\{2-[(3-metoxiphenyl) phenylamino]ethyl\} acetamide (UCM765) and $\mathrm{N}$-\{2-([3-bromophenyl]-4-fluorophenylamino)ethyl acetamide (UCM924) as partial $\mathrm{MT}_{2}$ receptor agonists. The animal models of acute and inflammation pain included hot-plate and formalin tests. The maximum antinociceptive effect was produced by $20 \mathrm{mg} / \mathrm{kg}$ of UCM765 and UCM924 and was comparable to $200 \mathrm{mg} / \mathrm{kg}$ of acetaminophen and $3 \mathrm{mg} / \mathrm{kg}$ of ketorolacum [40]. Altogether, these data demonstrated that selective $\mathrm{MT}_{2}$ receptor partial agonists had analgesic properties through modulation of brainstem descending antinociceptive pathways, and $\mathrm{MT}_{2}$ receptors may represent a novel target in the treatment of neuropathic pain $[39,40]$.

Interestingly, the $\mathrm{MT}_{1}$ and $\mathrm{MT}_{2}$ receptor localization differs. $\mathrm{MT}_{1}$ receptors are found in the spleen, hippocampus dentate gyrus, the islands of Calleja (in the striatum), suprachiasmatic nuclei, the superior colliculi of the corpora quadrigemina, the black substance, etc. $\mathrm{MT}_{2}$ receptors are predominantly found in the hippocampus CA3 subfield, thalamic reticular nucleus, supraoptic nucleus, the inferior colliculus of the corpora quadrigemina, and ventrolateral parts of the periaqueductal gray [41]. The different localization of $\mathrm{MT}_{1}$ and $\mathrm{MT}_{2}$ receptors indicates that they play different roles and perform different functions, which should be kept in mind when selective $\mathrm{MT}_{1}$ and $\mathrm{MT}_{2}$ agonists are used [42].

As for nuclear receptors, on one hand, RZR $\beta$ plays a specific role of a transcription factor in the sensory system, and on the other hand, $\mathrm{RZR} \alpha$ melatonin receptors are involved in inflammatory reactions. Steinhilber et al. [43] reported that melatonin can decrease the 


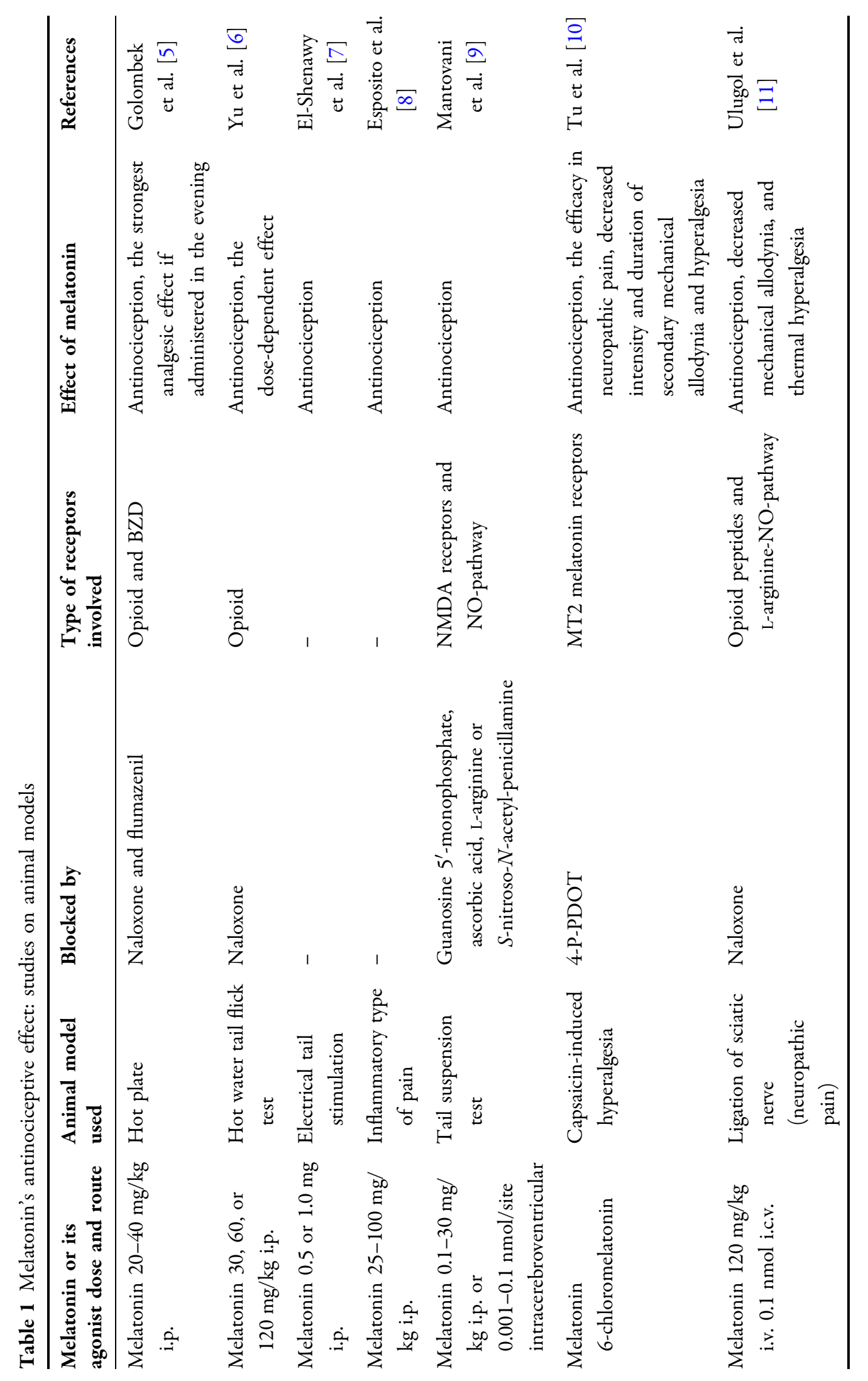




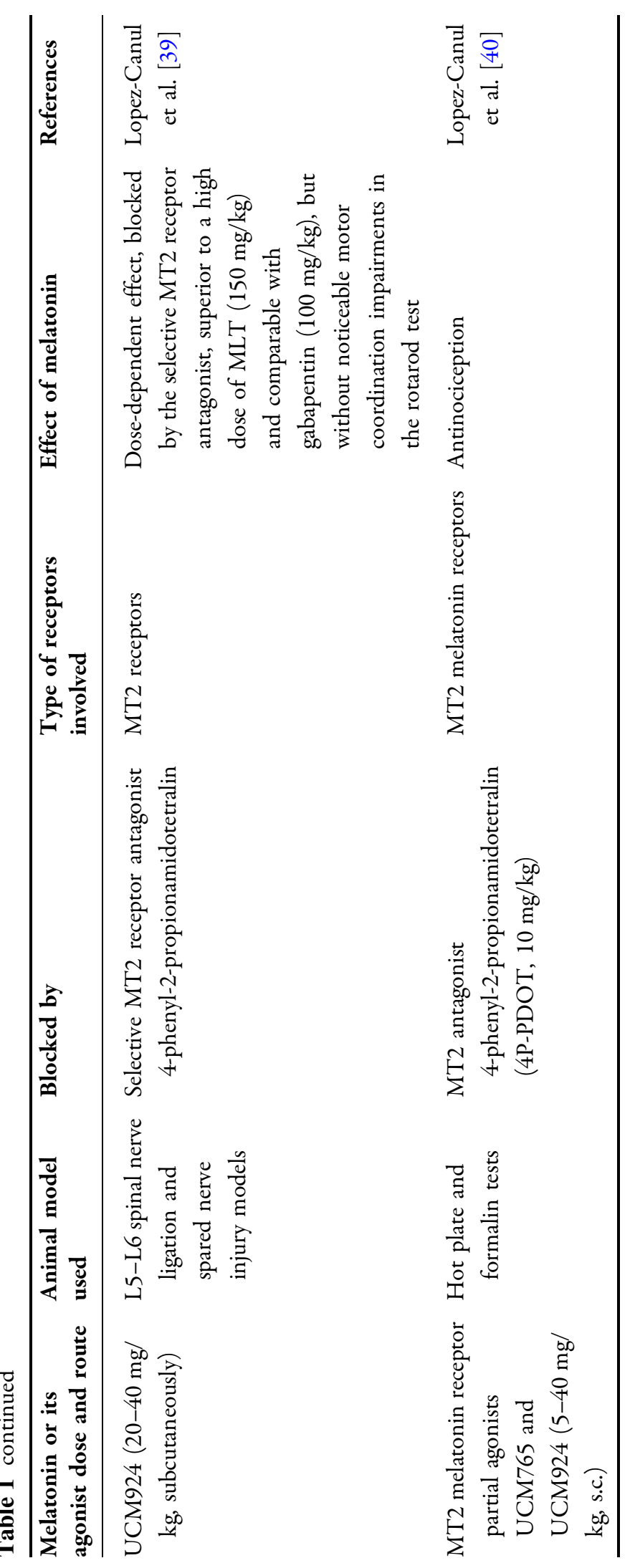




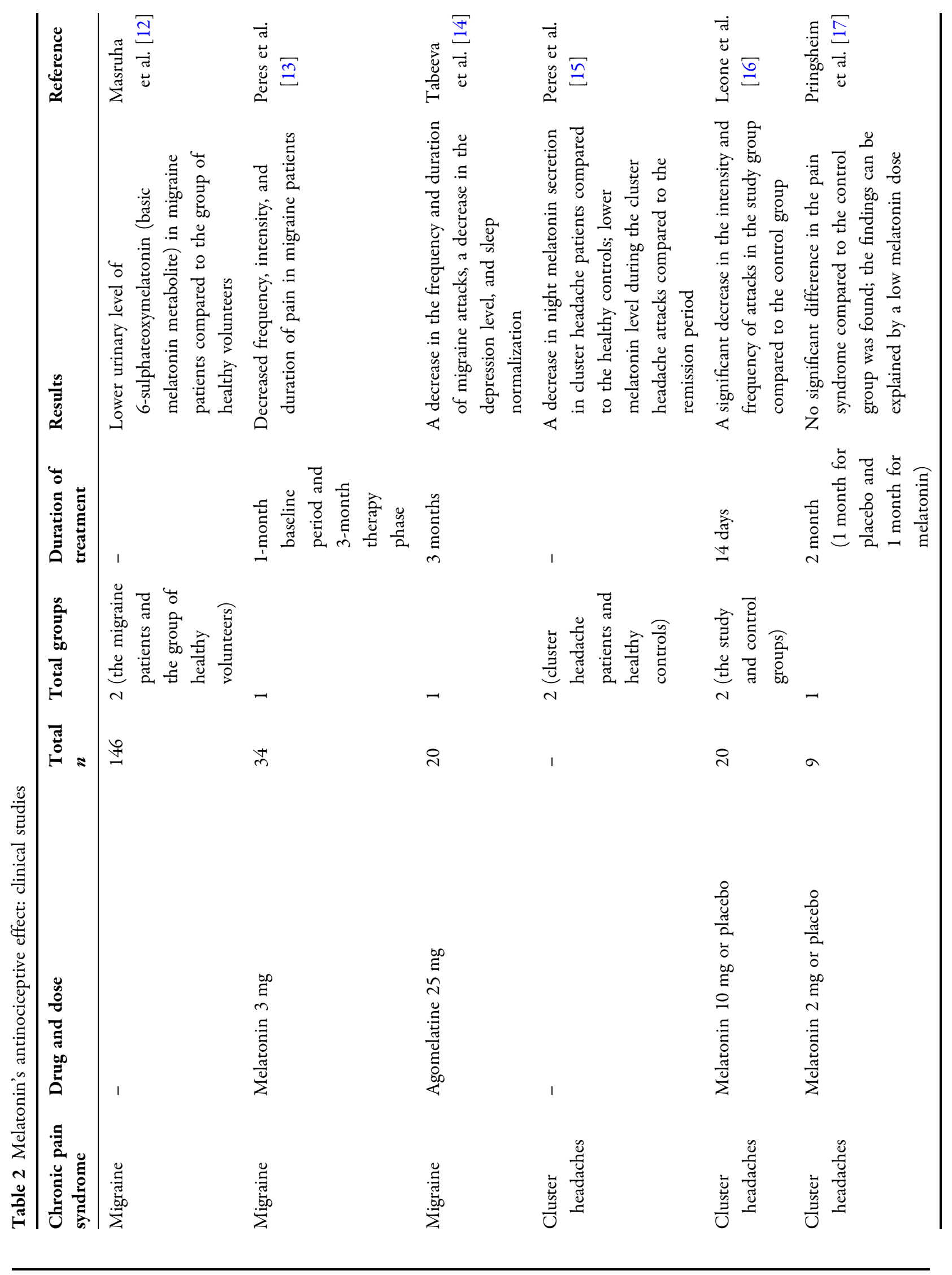




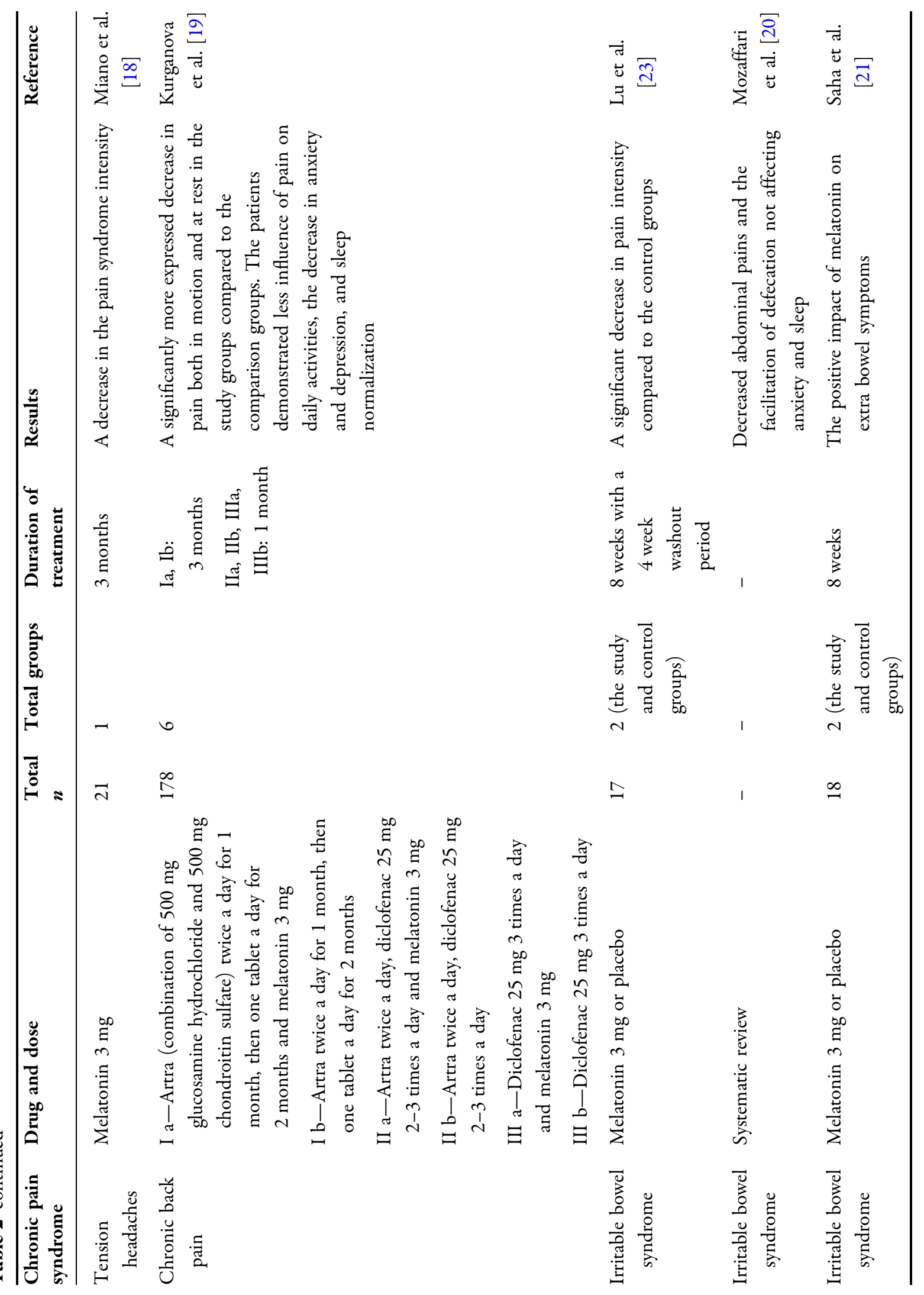




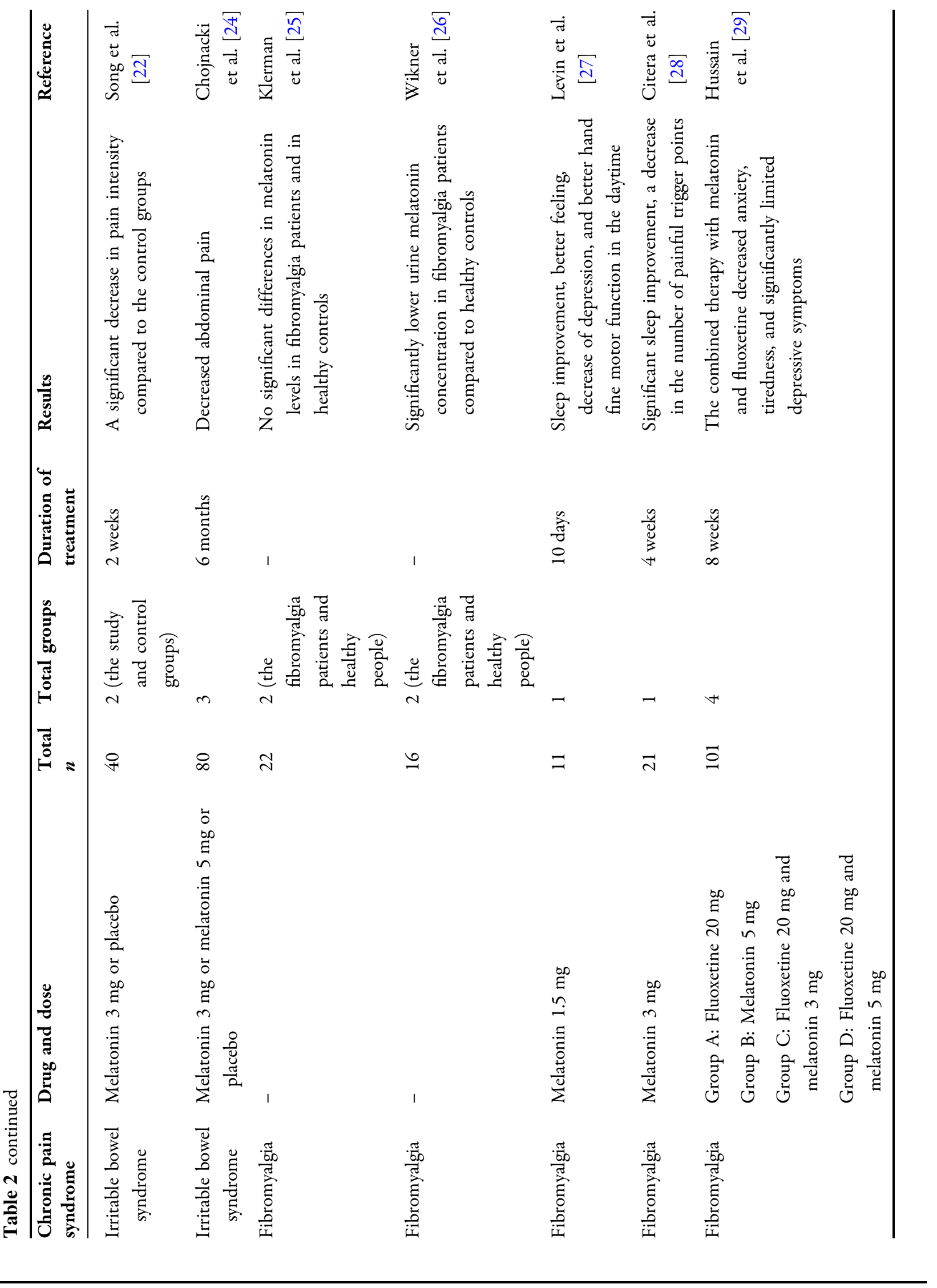




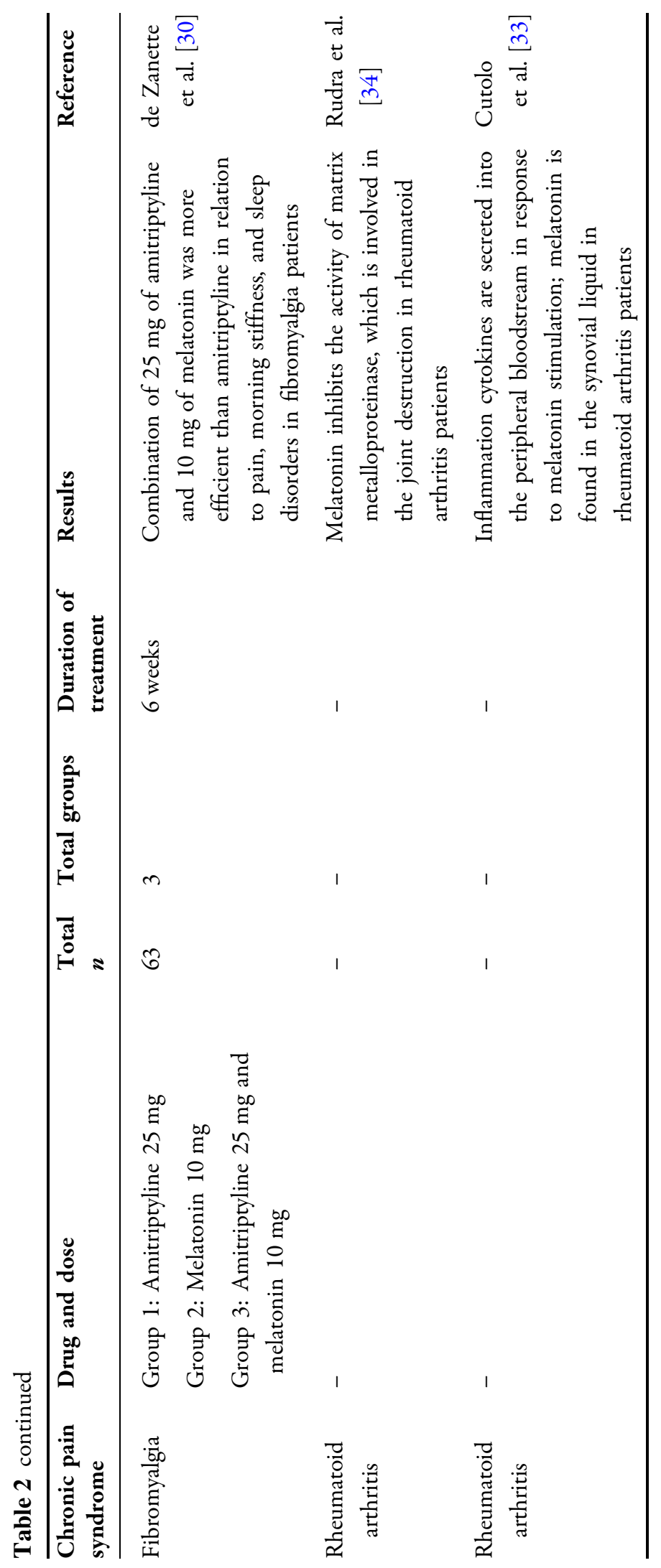


expression of 5-lipooxygenase (5-LOX), an important inflammatory mediator, in B-lymphocytes through RZR $\alpha$ receptors.

\section{The Influence on Ion Channels}

The experiments demonstrated that the antinociceptive effects of melatonin at least partially involve the activation of calcium channels. At the cell level, melatonin activates G-protein coupled Kir3 channels that in turn inhibit a series of action potentials in neurons. Moreover, melatonin activates $\mathrm{K}+$ ion release in the cerebellum cells, suprachiasmatic nucleus, and other areas of the nerve system [44].

The calcium channels play a decisive role in the development and maintenance of central sensitization associated with inflammation and neuropathic pain-it is the very effect that mediates the effect of Gabapentin which widely used for neuropathic pain treatment. Ayar et al. [45] demonstrated that melatonin inhibits $\mathrm{Ca}^{2+}$ entry into the neurons of dorsal root ganglia. It results from $\mathrm{Ca}^{2+}$ channel blockade and a consequent decrease of intracellular free $\mathrm{Ca}^{2+}$ concentration.

\section{Melatonin and GABA}

There is evidence suggesting that the central effects of melatonin involve the facilitation of GABAergic transmission by GABA receptor modulation. The epiphysis is connected via afferent fibers with the suprachiasmatic nucleus, which in turn is connected with the subparaventricular area and the dorsomedial nucleus. The neurons in the suprachiasmatic nucleus can provide both excitation and inhibition of the subparaventricular nucleus and the ventrolateral preoptic nucleus (these mechanisms are mediated by glutamate and
GABA, respectively). It was mentioned before that melatonin inhibits a series of action potentials in the neurons of the suprachiasmatic nucleus that may cause the loss of inhibition (and the consequent excitement of the structures innerved from the suprachiasmatic nucleus) or the loss of excitation (leading to increase in inhibition). Moreover, melatonin may modulate the functions of GABA receptors [46]. The experiments revealed that melatonin increases GABA affinity to the receptors in a rat's brain [64]. Melatonin and its analogues can bind to GABA receptors. Moreover, melatonin increases GABA concentration by $50 \%$ [47]. Thus, the data suggest a significant interconnection between melatonin and GABAergic systems, and some of the melatonin neuropharmacologic effects (including hypnotic activity) are evidently mediated through GABA receptors and may be blocked by GABA antagonists.

\section{CONCLUSIONS}

The effects of melatonin are still being researched. Some of these effects remain debatable, while others are doubtless. The analgesic effect of melatonin is among the latter. Its effects in relation to pain were demonstrated in several experimental studies on animal models and clinical trials with patients with various pain syndromes. That leads to understanding that melatonin antinociceptive mechanisms have a complex structure. On one hand, being a chronobiotic melatonin restores circadian rhythms, increasing the adaptive capabilities of the body. On the other hand, the anxiolytic effect of melatonin leads to a decrease in pain through the decrease of anxiety and vegetative reactions. 
Finally, there is a separate analgesic effect of melatonin on the melatonin receptors in the areas of the brain responsible for pain perception and control and on several neurotransmitter systems (GABA, opioid system, L-arginine/NO pathway, etc.). It is noteworthy that melatonin has a very high safety profile. The literature describes the potential adverse effects of melatonin, including day sleepiness, headaches, vertigo, abdominal discomfort, irritability, and confusion. However, in practice, clinical trials in various pain syndromes revealed an extremely low level of adverse effects.

It is no doubt that it is too early to consider melatonin as an analgesic. Nevertheless, given melatonin's potential in relation to both neuropathic and nociceptive pain, melatonin deserves special attention and may become an efficient addition to the existing drugs for pain syndrome treatment.

\section{ACKNOWLEDGMENTS}

No funding or sponsorship was received for the publication of this article. All named authors meet the International Committee of Medical Journal Editors (ICMJE) criteria for authorship for this manuscript, take responsibility for the integrity of the work as a whole, and have given final approval for the version to be published.

Disclosures. Andrei Danilov and Julia Kurganova have nothing to disclose.

Compliance with Ethics Guidelines. This article is based on previously conducted studies and does not involve any new studies of human or animal subjects performed by any of the authors.
Open Access. This article is distributed under the terms of the Creative Commons Attribution-NonCommercial 4.0 International License (http://creativecommons.org/licenses/ by-nc/4.0/), which permits any noncommercial use, distribution, and reproduction in any medium, provided you give appropriate credit to the original author(s) and the source, provide a link to the Creative Commons license, and indicate if changes were made.

\section{REFERENCES}

1. Lucas RJ, Lall GS, Allen AE, Brown TM. How rod, cone, and melanopsin photoreceptors come together to enlighten the mammalian circadian clock. Prog Brain Res. 2012;199:1-18.

2. Srinivasan V, Pandi-Perumal SR, Maestroni GJ, Esquifino AI, Hardeland R, Cardinali DP. Role of melatonin in neurodegenerative diseases. Neurotox Res. 2005;7:293-318.

3. Pandi-Perumal SR, Srinivasan V, Maestroni GJM, Cardinali DP, Poeggeler B, Hardeland R. Melatonin: nature's most versatile biological signal? FEBS J. 2006;273:2813-38.

4. Liu Y, He H, Huang F. Melatonin in pain modulation: analgesic or proalgesic? Pain Stud Treat. 2014;2:50-5.

5. Golombek DA, Escolar E, Burin LJ, Bristo-Sanchez MG, Cardinali DP. Time-dependent melatonin analgesia in mice: inhibition by opiate or benzodiazepine antagonism. Eur J Pharmacol. 1991;194:25-30.

6. Yu CX, Zhu B, Xu SF, Cao XD, Wu GC. The analgesic effects of peripheral and central administration of melatonin in rats. Eur J Pharmacol. 2000;403:49-53.

7. El-Shenawy SM, Abdel-Salam OM, Baiuomy AR, El-Batran S, Arbid MS. Studies on the anti-inflammatory and anti-nociceptive effects of melatonin in the rat. Pharmacol Res. 2002;46(3):235-43.

8. Esposito E, Paterniti I, Mazzon E, Bramanti P, Cuzzocrea S. Melatonin reduces hyperalgesia associated with inflammation. J Pineal Res. 2010;49(4):321-31. 
9. Mantovani M, Pértile R, Calixto JB, Santos AR, Rodrigues AL. Melatonin exerts an antidepressant-like effect in the tail suspension test in mice: evidence for involvement of $\mathrm{N}$-methyl-D-aspartate receptors and the L-arginine-nitric oxide pathway. Neurosci Lett. 2003;343(1):1-4.

10. Tu Y, Sun RQ, Willis WD. Effects of intrathecal injections of melatonin analogs on capsaicin-induced secondary mechanical allodynia and hyperalgesia in rats. Pain. 2004;109(3):340-50.

11. Ulugol A, Dokmeci D, Guray G, Sapolyo N, Ozyigit F, Tamer M. Antihyperalgesic, but not antiallodynic, effect of melatonin in nerve-injured neuropathic mice: possible involvements of the L-arginine-NO pathway and opioid system. Life Sci. 2006;78(14):1592-7.

12. Masruha MR, de Souza Viera DS, Minett TS, Cipolla-Neto J, Zuckerman E, Vilanova LC, Peres MF. Low urinary 6-sulphatoxy-melatonin concentrations in acute migraine. J Headache Pain. 2008;9:221-34.

13. Peres MF, Zukerman E, da Cunha Tanuri F, Moreira FR, Cipolla-Neto J. Melatonin, $3 \mathrm{mg}$, is effective for migraine prevention. Neurology. 2004;63:757.

14. Tabeeva GR, Sergeev AV, Gromova SA. Possibilities of preventive treatment of migraine with MT1 and MT2 agonist and 5-HT2c receptor antagonist agomelatine (Valdoxan). Zh Nevrol Psikhiatr Im S S Korsakova. 2011;111(9):32-6.

15. Peres MFP, Masruha MR, Zukerman E, et al. Potential therapeutic use of melatonin in migraine and other headache disorders. Expert Opin Investig Drugs. 2006;15(4):367-75.

16. Leone M, D'Amico D, Moschiano F, et al. Melatonin versus placebo in the prophylaxis of cluster headache: a double-blind pilot study with parallel groups. Cephalalgia. 1996;16:494-6.

17. Pringsheim T, Magnoux E, Dobson CF, et al. Melatonin as adjunctive therapy in the prophylaxis of cluster headache: a pilot study. Headache. 2002;42:787-92.

18. Miano S, Parisi P, Pellicci A, Luchetti A, Paolino MC, Villa MP. Melatonin to prevent migraine or tension-type headache in children. Neurol Sci. 2008;29(4):285-7.

19. Kurganova JM, Danilov AB. A role of melatonin in the treatment of low back pain. Zh Nevrol Psikhiatr Im S S Korsakova. 2015;4:30-5.
20. Mozaffari S, Rahimi R, Abdollahi M. Implications of melatonin therapy in irritable bowel syndrome: a systematic review. Curr Pharm Des. 2010;16(33):3646-55.

21. Saha L, Malhotra S, Rana S, Bhasin D, Pandhi P. A preliminary study of melatonin in irritable bowel syndrome. J Clin Gastroenterol. 2007;41(1):29-32.

22. Song GH, Leng PH, Gwee KA, Moochhala SM, Ho KY. Melatonin improves abdominal pain in irritable bowel syndrome patients who have sleep disturbances: a randomised, double blind, placebo-controlled study. Gut. 2005;54:1402-7.

23. Lu WZ, Gwee KA, Moochhalla S, Ho KY. Melatonin improves bowel symptoms in female patients with irritable bowel syndrome: a double-blind placebo-controlled study. Aliment Pharmacol Ther. 2005;22(10):927-34.

24. Chojnacki C, Walecka-Kapica E, Lokieć K, Pawłowicz M, Winczyk K, Chojnacki J, Klupińska G. Influence of melatonin on symptoms of irritable bowel syndrome in postmenopausal women. Endokrynol Pol. 2013;64:114-20.

25. Klerman EB, Goldenberg DL, Brown EN, Maliszewski AM, Adler GK. Circadian rhythms of women with fibromyalgia. J Clin Endocrinol Metab. 2001;86:1034-9.

26. Wikner J, Hirsch U, Wetterberg L, Rojdmark S. Fibromyalgia - a syndrome associated with decreased nocturnal melatonin secretion. Clin Endocrinol (Oxf). 1998;49:179-83.

27. Levin Ya. I. Melatonin (Melaxen) in neurological practice. Consilium Medicum 2012;No 02, p. 111-5.

28. Citera G, Arias MA, Maldonado-Cocco JA, et al. The effect of melatonin in patients with fibromyalgia: a pilot study. Clin Rheumatol. 2000;19:9-13.

29. Hussain SA, Al-Khalifa II, Jasim NA, Gorial FI. Adjuvant use of melatonin for treatment of fibromyalgia. J Pineal Res. 2011;50:267-71.

30. de Zanette SA, Vercelino R, Laste G, Rozisky JR, Schwertner A, Machado CB, Xavier F, de Souza IC, Deitos A, Torres IL, Caumo W. Melatonin analgesia is associated with improvement of the descending endogenous pain-modulating system in fibromyalgia: a phase II, randomized, double-dummy, controlled trial. BMC Pharmacol Toxicol. 2014;15:40.

31. Cutolo M, Maestroni GJM, Otsa K, et al. Circadian melatonin and cortisol levels in rheumatoid arthritis patients in winter time: a north and south Europe comparison. Ann Rheum Dis. 2005;64(2):212-6. 
32. Afkhamizadeh M, Sahebari M, Seyyed-Hoseini SR. Morning melatonin serum values do not correlate with disease activity in rheumatoid arthritis: a cross-sectional study. Rheumatol Int. 2014;34(8):1145-51.

33. Cutolo M, Maestroni GJM. The melatonin-cytokine connection in rheumatoid arthritis. Ann Rheum Dis. 2005;64(8):1109-11.

34. Rudra DS, Pal U, Maiti NC, Reiter RJ, Swarnakar S. Melatonin inhibits matrix metalloproteinase-9 activity by binding to its active site. J Pineal Res. 2013;54(4):398-405.

35. Reppert SM, Weaver DR, Ebisawa T. Cloning and characterization of a mammalian melatonin receptor that mediates reproductive and circadian responses. Neuron 1994;1177-85.

36. Vanecek J. Cellular mechanisms of melatonin action. Physiol Rev. 1998;78(3):687-721.

37. Zahn PK, Lansmann T, Berger E, Speckmann EJ, Musshoff U. Gene expression and functional characterization of melatonin receptors in the spinal cord of the rat: implications for pain modulation. J Pineal Res. 2003;35(1):24-31.

38. Wilhelmsen M, Amirian I, Reiter RJ, Rosenberg J, Gögenur I. Analgesic effects of melatonin: a review of current evidence from experimental and clinical studies. J Pineal Res. 2011;51(3):270-7.

39. Lopez-Canul M, Palazzo E, Dominguez-Lopez S, Luongo L, Lacoste B, Comai S, Angeloni D, Fraschini F, Boccella S, Spadoni G, Bedini A, Tarzia G, Maione S, Granados-Soto V, Gobbi G. Selective melatonin MT2 receptor ligands relieve neuropathic pain through modulation of brainstem descending antinociceptive pathways. Pain. 2015;156(2):305-17.

40. López-Canul M, Comai S, Domínguez-López S, Granados-Soto V, Gobbi G. Antinociceptive properties of selective MT2 melatonin receptor partial agonists. Eur J Pharmacol. 2015;5(764):424-32.

41. Lacoste B, Angeloni D, Dominguez-Lopez S, Calderoni S, Mauro A, Fraschini F, Descarries L, Gobbi G. Anatomical and cellular localization of melatonin MT1 and MT2 receptors in the adult rat brain. J Pineal Res. 2015;58(4):397-417.

42. Liu J, Clough SJ, Hutchinson AJ, Adamah-Biassi EB, Popovska-Gorevski M, Dubocovich ML. MT1 and MT2 melatonin receptors: a therapeutic perspective. Annu Rev Pharmacol Toxicol. 2016;6(56):361-83.

43. Steinhilber D, Brungs M, Werz O, Wiesenberg I, Danielsson C, Kahlen JP, Nayeri S, Schrader M, Carlberg C. The nuclear receptor for melatonin represses 5-lipoxygenase gene expression in human B lymphocytes. J Biol Chem. 1995;270(13):7037-40.

44. Wang LM, Suthana NA, Chaudhury D, Weaver DR, Colwell CS. Melatonin inhibits hippocampal long-term potentiation. Eur J Neurosci. $2005 ; 22(9): 2231-7$.

45. Ayar A, Duncan JM, Ozcan M, Kelestimur $H$. Melatonin inhibits high voltage activated calcium currents in cultured rat dorsal root ganglion neurons. Neurosci Lett. 2001;313(1-2):73-7.

46. Wilhelmsen M, Amirian I, Reiter RJ, Rosenberg J, Gögenur I. Analgesic effects of melatonin: a review of current evidence from experimental and clinical studies. J Pineal Res. 2011;51(3):270-7.

47. $\mathrm{Xu} \mathrm{F}, \mathrm{Li} \mathrm{JC}, \mathrm{Ma} \mathrm{KC}$, et al. Effects of melatonin on hypothalamic gamma-aminobutyric acid, aspartic acid, glutamic acid, beta-endorphin and serotonin levels in male mice. Biol Signals. 1995;4:225-31. 